\title{
NSW Health COVID-19 Emergency Response Priority Research program: a case study of rapid translation of research into health decision making
}

\author{
Danielle Campbella,b, Barry Edwards ${ }^{a}$, Andrew Milata ${ }^{a}$, Sarah Thackway ${ }^{a}$, \\ Elizabeth Whittaker ${ }^{a}$, Laura Goudswaard ${ }^{a}$, Michelle Cretikos ${ }^{a}$, Antonio \\ Penna a and Kerry Chanta
}

${ }^{a}$ NSW Ministry of Health, Sydney, Australia

b Corresponding author: danielle.campbell@health.nsw.gov.au

\section{Article history}

Publication date: 10 November 2021 Citation: Campbell D, Edwards B, Milat A Thackway S, Whittaker E, Goudswaard L, Cretikos M, Penna A, Chant K. NSW Health COVID-19 Emergency Response Priority Research program: a case study of rapid translation of research into health decision making. Public Health Res Pract. 2021;31(4):e3142124. https://doi. org/10.17061/phrp3142124

\section{Key points}

- The Emergency Response Priority Research (Emergency Response) workstream was established by NSW Health in 2020 for the rapid creation of evidence to support public health management of COVID-19

- Nine Emergency Response research projects were expedited between April 2020 and June 2021, drawing on local research expertise, existing research projects, and established research partnerships

\section{Abstract}

Objectives: The NSW Health COVID-19 Research Program was established in April 2020 to contribute to minimising the health, social and economic impacts of the coronavirus disease 2019 (COVID-19) pandemic in New South Wales (NSW). This paper describes the establishment and implementation of one element of the Program, the Emergency Response Priority Research (Emergency Response) workstream, which is focused on the rapid creation of evidence to support urgent operational work for the public health management of COVID-19 in NSW.

Methods: Narrative description.

Results: As at June 2021, nine Emergency Response projects had been funded. Mechanisms used to expedite projects included: embedding academic researchers in NSW Health to work directly with routinely collected NSW Health data; adapting existing research projects to include a COVID-19 component; leveraging established research partnerships to conduct rapid pilots; and directly commissioning urgent projects with experienced and trusted local researchers.

Lessons learnt: Evidence from Emergency Response projects has contributed directly to informing the NSW public health response. For example, findings from a study of COVID-19 transmission in schools and childcare settings in the early stages of the pandemic informed decisions around the resumption of on-campus education in 2020 and helped shape policy around higher risk activities to help reduce transmission in education settings. Similarly, findings from a project to validate methods for identifying SARS-CoV-2 virus fragments in wastewater were subsequently incorporated 
- Evidence from these projects has contributed directly to informing the NSW public health response to COVID-19 across a number of areas

- This highlights the value of health systems being supported by a well-trained public health research community and collaborative research sector into the NSW Sewage Surveillance Program, which continues to provide NSW Health with information to support targeted messaging and testing.

The approach to establishing and implementing the Emergency Response workstream highlights the importance of continuing to ensure a well-trained public health research community and actively supporting a collaborative research sector.

\section{Introduction}

The coronavirus disease 2019 (COVID-19) pandemic has required health system decision makers worldwide to act rapidly in an evolving context to limit disease transmission and optimise patient care. In this environment, expedited evidence from both routinely collected data and primary research is invaluable for informing health system and public health responses.

In New South Wales (NSW), the State Government response built on previous pandemic planning that was informed by lessons from the severe acute respiratory syndrome (SARS) and H1N1 influenza outbreaks. ${ }^{1}$ The NSW Health operational response was coordinated via the Public Health Response Branch - responsible for case finding, contact tracing, outbreak control and other preventive actions - and the State Health Emergency Operations Centre - responsible for managing and overseeing clinical operations, health workforce support and procurement of personal protective equipment. The operational response was augmented by the formation in March 2020 of a series of 30 specialityspecific Communities of Practice (COPs) representing services at the frontline of the COVID-19 response and associated roles. COP clinical leads participated in a multidisciplinary COVID-19 Clinical Council which was responsible for escalating issues and providing expert advice to operational arms of NSW Health. ${ }^{2}$ A Critical Intelligence Unit was also established as a non-decisionmaking resource at arm's length from operational functions to provide objective, real-time advice in line with a changing evidence base. ${ }^{3}$

Alongside the operational response, in April 2020 the NSW Government announced funding of \$25 million to fast-track research to support the NSW COVID-19 response and recovery. As a result, the COVID-19 Research Program was established to contribute to minimising the health, social and economic impacts of the COVID-19 pandemic in NSW. Generating local evidence was acknowledged as particularly important in the context of Australia's early pandemic response, which resulted in relatively low population and case fatality rates compared with other countries.

The NSW COVID-19 Research Program consists of seven interconnected workstreams encompassing funding and expedited administrative processes for COVID-19 research, and support for clinical trials and industry schemes. Funding for research was provided through two separate workstreams:
1. The COVID-19 Research Grants workstream established a pathway to create knowledge and innovations to support the COVID-19 pandemic response through two rounds of funding. Round 1 was a rapid funding round launched in May 2020 with short application and review timeframes; it was designed for projects with capacity to commence within 4 weeks of funding and report on interim outcomes within 6 months. ${ }^{4}$ Round 2 was aimed at proposals requiring a longer development period with funding provided over 2 years. ${ }^{5}$ Seven targeted studies were funded in Round 1 and 10 studies were funded in Round 2.

\section{The Emergency Response Priority Research}

(Emergency Response) workstream enabled rapid creation of evidence to support urgent operational work for the public health management of the COVID-19 epidemic in NSW.

This paper provides an overview of the establishment and implementation of the Emergency Response workstream, including how research findings have helped to inform the NSW public health response.

\section{Establishment of the Emergency Response Priority Research workstream}

Emergency Response research projects were established outside the COVID-19 Research Grants rounds to create evidence to support urgent operational work for public health management of the epidemic in NSW. Projects supported through this stream were identified by the NSW Chief Health Officer in consultation with the NSW Public Health Response Branch and met the following criteria:

- The evidence need is so urgent for operational decisions that it cannot wait for a targeted research funding process

- The evidence directly supports the NSW health system's pandemic response

- The project requires research and analytical resources external to the NSW Ministry of Health to deliver it (including where internal resources were fully allocated to other aspects of the pandemic response).

As at June 2021 the Emergency Response workstream consisted of nine funded research projects (Table 1). 
Table 1. Emergency Response Priority Research workstream projects

\begin{tabular}{|c|c|c|}
\hline Project title & Project summary & Research lead \\
\hline $\begin{array}{l}\text { NSW Health COVID- } 19 \text { schools } \\
\text { transmission investigation project }\end{array}$ & $\begin{array}{l}\text { A study to document transmission in school } \\
\text { and childcare settings, with enhanced } \\
\text { investigations via home/school visits of close } \\
\text { contacts }\end{array}$ & NCIRS \\
\hline $\begin{array}{l}\text { Serosurveillance for SARS-CoV-2 } \\
\text { infection }\end{array}$ & $\begin{array}{l}\text { A cross-sectional serosurvey of residual } \\
\text { blood specimens collected April-June } 2020 \\
\text { to estimate SARS-CoV- } 2 \text { specific antibody } \\
\text { seroprevalence among three subpopulations in } \\
\text { Sydney }\end{array}$ & $\begin{array}{l}\text { NCIRS, UNSW Sydney, Institute } \\
\text { of Clinical Pathology and Medical } \\
\text { Research }\end{array}$ \\
\hline COVID-19 NSW Outcomes Study & $\begin{array}{l}\text { Cross-sectional analysis of confirmed } \\
\text { COVID-19 cases linked to routinely collected } \\
\text { hospitalisation data to determine disease } \\
\text { severity and hospital utilisation and underlying } \\
\text { causes of admission }\end{array}$ & UNSW Sydney \\
\hline $\begin{array}{l}\text { Retrospective infected healthcare worker } \\
\text { study }\end{array}$ & $\begin{array}{l}\text { Case series and case control studies of health } \\
\text { facility acquired COVID-19 in NSW healthcare } \\
\text { workers }\end{array}$ & UNSW Sydney \\
\hline $\begin{array}{l}\text { Burden of influenza-like illness (ILI) } \\
\text { disease in adults } \geq 65 \text { years in aged care } \\
\text { facilities }\end{array}$ & $\begin{array}{l}\text { A study to estimate attack, hospitalisation } \\
\text { and death rates of viral respiratory infection } \\
\text { outbreaks in aged care facilities }\end{array}$ & $\begin{array}{l}\text { University of Sydney, Western Sydney } \\
\text { Local Health District }\end{array}$ \\
\hline $\begin{array}{l}\text { The Australian First Few 'X' (FFX) } \\
\text { Project for COVID-19a }\end{array}$ & $\begin{array}{l}\text { National prospective case-ascertained } \\
\text { transmission study involving collection of } \\
\text { enhanced data and specimens from laboratory } \\
\text { confirmed cases and household contacts to } \\
\text { study household transmission }\end{array}$ & NCIRS \\
\hline $\begin{array}{l}\text { Wastewater-based epidemiology for } \\
\text { COVID-19 - validation pilot }\end{array}$ & $\begin{array}{l}\text { Validation of Sydney Water analysis protocol for } \\
\text { SARS-CoV-2 detection in sewage }\end{array}$ & Sydney Water, NSW Health \\
\hline $\begin{array}{l}\text { Monitoring and investigating the safety } \\
\text { and effectiveness of the COVID-19 } \\
\text { vaccination program }\end{array}$ & $\begin{array}{l}\text { Project to strengthen vaccine safety } \\
\text { surveillance systems to rapidly detect, } \\
\text { investigate, assess, report and respond to } \\
\text { adverse events following immunisation }\end{array}$ & NCIRS \\
\hline $\begin{array}{l}\text { Surveillance of paediatric COVID-19, } \\
\text { Kawasaki disease and PIMS-TS via } \\
\text { PAEDS }\end{array}$ & $\begin{array}{l}\text { Active prospective hospital surveillance for } \\
\text { paediatric COVID-19 cases and potentially } \\
\text { related conditions }\end{array}$ & Sydney Children's Hospitals Network \\
\hline
\end{tabular}

NCIRS = National Centre for Immunisation Research and Surveillance; PAEDS = Paediatric Active Enhanced Disease Surveillance; PIMS-TS =

Paediatric Inflammatory Multisystem Syndrome Temporarily associated with SARS-CoV-2.

a Although the national FFX study is funded by the Australian Government Department of Health and the National Health and Medical Research Council, through the APPRISE Centre of Research Excellence, initial funds were provided by NSW Health for rapid establishment and data collection in NSW.

\section{Mechanisms to expedite}

\section{Emergency Response projects}

The Emergency Response workstream leveraged existing research infrastructure, agreements and partnerships to directly engage researchers who could rapidly generate local evidence to inform policy and practice throughout the COVID-19 pandemic (Box 1).

Mechanisms to expedite research projects included:

- Embedding research personnel in NSW Health to work directly with NSW Health datasets to inform the pandemic response. For example, the COVID-19 NSW
Outcomes Study ${ }^{7-9}$ was led by a senior epidemiologist with expertise in linked data analysis, seconded from the university sector and embedded in the Public Health Response Branch to work directly with routinely collected health data.

- Adapting existing research projects to collect local evidence. The Burden of Influenza-Like IIIness (ILI) study involved adaptation of an existing study of ILI in adults aged 65 years and older in residential aged care settings to include COVID-19 surveillance.

- Leveraging existing research partnerships. An established partnership between NSW Health and Sydney Water enabled rapid piloting of a new method 
for detecting SARS-CoV-2 in untreated sewage that subsequently grew into a comprehensive surveillance system (Box 2).

- Direct commissioning of new COVID-19 research projects with experienced and trusted NSW researchers. For example, researchers with longstanding involvement in national serosurveillance programs were rapidly engaged to undertake accelerated serological surveys ${ }^{10}$ in metropolitan Sydney to contribute to the Enhanced Surveillance Plan for COVID-19 in NSW.

\section{Impact of Emergency Response Priority Research}

Evidence identified from several Emergency Response research projects contributed directly to informing the NSW public health response and helping to keep the NSW population healthy and safe.

For example, findings from the schools study in the early stages of the pandemic ${ }^{6}$ contributed to the decision to resume on-campus education in mid-2020, after a period where most NSW children were engaged in remote learning. It also helped to shape policy around higherrisk school activities (such as singing and overnight

Box 1. Case study: local evidence about COVID-19 in children and young people in educational settings

Early in the COVID-19 response, NSW Health required local evidence to inform decisions about whether schools should operate face to face, as closures and distance learning arrangements would have significant social and economic impacts. Outbreaks in schools in the initial stages of the pandemic (Term 1, 2020) highlighted that information was urgently required by NSW Health and the NSW Department of Education.

The National Centre for Immunisation Research and Surveillance (NCIRS), established by the Australian Government in 1997 to provide independent advice on all aspects of immunisation, is the leading research organisation in Australia focused on vaccine preventable diseases. Existing relationships between NSW Health and NCIRS enabled the rapid establishment of an enhanced surveillance study among staff and children in NSW schools and early childhood care settings. The study was conducted with input from key stakeholders from the NSW Department of Education, NSW Health Pathology and several local health district public health units.

The NSW findings ${ }^{6}$ were consistent with concurrent international studies, demonstrating low SARS-CoV-2 transmission rates in children, and provided current, high-quality local evidence to inform decisions about safely returning to face-to-face learning in NSW in mid-2020. excursions) to support reduced transmission while schools are operating. This had broader social and economic benefits of enabling children and educators to engage in valuable in-person education, allowing parents and carers to return to work, permitting essential workers to deliver services, and businesses and workplaces to continue operations, while maintaining low rates of secondary transmission within educational settings.

Methods validated through the wastewater testing pilot have been incorporated into the NSW Sewage Surveillance Program, which continues to provide critical intelligence via daily reporting of test results to NSW Health, other state and territory jurisdictions and the Australian Government, as well as to the public, on the NSW Health website. ${ }^{14}$ Findings from the Surveillance Program have enabled NSW Health to target messaging and testing to high-risk areas, tracking possible COVID-19 clusters and outbreaks and managing movement restrictions following a known outbreak. For example, in the Northern Beaches region (an outer-suburban area of metropolitan Sydney), COVID-19 viral fragments were detected in sewage on 16 December 2020, the same day as two confirmed clinical cases of COVID-19 in the area. Findings were published and testing increased from 1 per 1000 residents to more than 90 per 1000 residents by 20 December. ${ }^{15}$ The specificity of the data contributed to the Northern Beaches being segmented into upper and lower regions, with stricter restrictions in the upper region including limited movement out of the area. Continued monitoring of COVID-19 detections in sewage also informed subsequent easing of restrictions in the lower region.

Box 2. Case study: COVID-19 wastewater monitoring

Early in the COVID-19 pandemic it was established that fragments of the COVID-19 (SARS-CoV-2) virus could be detected in untreated sewage, providing an opportunity to track infections in the community alongside existing testing efforts. ${ }^{11}$

A collaboration of NSW Health, Sydney Water, Water Research Australia's Australia-wide Collaboration on Sewage Surveillance of SARS-CoV-2 (ColoSSoS) and UNSW Sydney was funded under the Emergency Response workstream to validate a novel method for detecting SARS-CoV-2 fragments in wastewater. ${ }^{12}$

The project rapidly pivoted existing technology to verify the sensitivity and specificity of the approach, with additional funding subsequently provided by NSW Health to operationalise the method and establish a state-wide COVID-19 wastewater surveillance program. A microbiological sampling procedure and checklist for COVID-19 sewage surveillance have been produced, and technical knowledge including methods and protocols have been shared internationally. ${ }^{13}$ 
The Emergency Response research projects have generated other benefits that will continue to support the local pandemic response. The serosurveillance study ${ }^{10}$ established a feasible framework for repeatable examination of SARS-CoV-2 transmission over time, with similar methods used since in a national serosurvey. Linkage of data about COVID-19 cases from the NSW Health Notifiable Conditions Information Management System with unit record data from the NSW Admitted Patient Data Collection for the COVID-19 NSW Outcomes Study ${ }^{7-9}$ will enable more automated analyses of disease morbidity over time.

\section{Conclusion}

Globally the COVID-19 pandemic has triggered the establishment of numerous rapid research funding mechanisms, with researchers encouraged and supported to redirect their efforts towards pandemicrelated priorities. ${ }^{16}$ In NSW, the agile response of highly skilled and experienced researchers in close partnership with policy makers through the Emergency Response Priority Research workstream has ensured health decision makers have the best possible local evidence on which to base operational decisions. The success of the Emergency Response projects highlights the value of a strong, collaborative health research sector, and the importance of a well-trained public health research community ${ }^{17}$ and an adequately skilled and qualified public health workforce. ${ }^{18}$

\section{Peer review and provenance}

Externally peer reviewed, invited.

\section{Competing interests}

None declared.

\section{Author contributions}

$\mathrm{DC}, \mathrm{BE}$ and $\mathrm{AM}$ drafted the manuscript. $\mathrm{KC}$ led the design of the research program described in the manuscript. ST, MC, AM, DC, BE and AP contributed to the design and management of the research program described in the manuscript. EW and LG led an evaluation of the research program described in the manuscript.

\section{References}

1. McAnulty JM, Ward K. Suppressing the epidemic in New South Wales. N Engl J Med. 2020;382(21):e74.

2. Lyons N, Cox C, Clements V. Value of clinical engagement in the NSW Health response to COVID-19. Aust Health Rev. 2021;45:306-7.
3. Levesque J-F, Sutherland K, Watson DE, Currow DC, Bolevich Z, Koff E. Learning systems in times of crisis: the COVID-19 Critical Intelligence Unit in New South Wales, Australia. US: NEJM Catalyst; 2020 Nov 23 [cited 2021 Oct 11]. Available from: catalyst.nejm.org/doi/full/10.1056/ CAT.20.0542

4. Office for Health and Medical Research. COVID-19 research grants round 1: guidelines. Sydney: NSW Ministry of Health; 2020 [cited 2021 Sep 21]. Available from: www.medicalresearch.nsw.gov.au/app/ uploads/2020/05/COVID-19-Research-Grants-RoundOne-Guidelines_2020.pdf

5. Office for Health and Medical Research. COVID-19 research grants round two: guidelines. Sydney: NSW Ministry of Health; 2020 [cited 2021 Sep 21]. Available from: www.medicalresearch.nsw.gov.au/app/ uploads/2020/07/COVID-19-Research-Grants-RoundTwo-Guidelines_2020.pdf

6. Macartney K, Quinn HE, Pillsbury AJ, Koirala A, Deng L, Winkler N, et al. Transmission of SARS-CoV-2 in Australian educational settings: a prospective cohort study. Lancet Child Adolesc Health. 2020;4:807-16.

7. Liu B, Spokes P, Alfaro-Ramirez M, Ward K, Kaldor J. Hospital outcomes after a COVID-19 diagnosis from January to May 2020 in New South Wales Australia. Commun Dis Intell. 2020;44.

8. Liu B, Jayasundara D, Pye V, Dobbins T, Dore GJ, Matthews $\mathrm{G}$, et al. Whole of population-based cohort study of recovery time from COVID-19 in New South Wales Australia. Lancet Reg Health West Pac. 2021;12:100193.

9. Liu B, Spokes P, He W, Kaldor J. High risk groups for severe COVID-19 in a whole of population cohort in Australia. BMC Infect Dis. 2021;21:685.

10. Gidding HF, Machalek D, Hendry AJ, Quinn HE, Vette K, Beard FH, et al. Seroprevalence of SARS-CoV-2-specific antibodies in Sydney, Australia following the first epidemic wave in 2020. Med J Aust. 2021;214(4):179-85.

11. Mallapaty S. How sewage could reveal true scale of coronavirus outbreak. Nature. 2020;580:176-77.

12. Camphor HS, Nielsen S, Bradford-Hartke Z, Wall K, Broome R. Retrospective epidemiological analysis of SARS-CoV-2 wastewater surveillance and case notifications data - New South Wales, Australia, 2020. J Water Health. 2021:jwh2021275.

13. The Water Research Foundation. Wastewater surveillance of the COVID-19 genetic signal in sewersheds: recommendations from global experts. Alexandria, VA: The Water Research Foundation; 2020 [cited 2021 July 8]. Available from: www.waterrf.org/sites/ default/files/file/2020-06/COVID-19_SummitHandout-v3b. pdf

14. NSW Health. COVID-19 weekly surveillance reports. Sydney: NSW Government; c2020-2021 [cited 2021 July 8]. Available from: www.health.nsw.gov.au/ Infectious/covid-19/Pages/weekly-reports.aspx 
15. NSW Health. COVID-19 weekly surveillance in NSW: Epidemiological week 51, ending 19 December 2020. Sydney: NSW Ministry of Health; 2020 [cited 2021 Oct 19]. Available from: www.health.nsw.gov.au/ Infectious/covid-19/Documents/covid-19-surveillancereport-20201219.pdf

16. OECD. Mobilising public research funding and infrastructures in times of crisis. In: OECD Science, Technology and Innovation Outlook 2021: Times of Crisis and Opportunity. Paris: OECD Publishing; 2021 [cited 2021 Sep 21]. Available from: www.oecd-ilibrary.org/sites/ e96ef24b-en/index.html?itemld=/content/component/ e96ef24b-en
17. Eley DS, O'Leary SP, Young A, Buttrum P. Is Australia's clinician scientist capacity appropriate for addressing the next pandemic? Aust Health Rev. 2021;45:308-10.

18. Johnston I, on behalf of PHAA. Australia's public health response to COVID-19: what have we done, and where to from here? Aust N Z J Public Health. 2020;4(6):440-5. 